\title{
The potential role of physical activity on driving performance and safety among older adults
}

\author{
José Marmeleira • Mário Godinho • Peter Vogelaere
}

Received: 15 July 2008 / Accepted: 9 February 2009/Published online: 11 March 2009

(C) European Group for Research into Elderly and Physical Activity (EGREPA) 2009

\begin{abstract}
The elderly represent the fastest growing driving population. Older drivers have a high crash rate per distance traveled, a high risk of injury or death in traffic accidents, and are commonly found to be 'at fault' in crashes. This reality has focused more interest on issues associated with the fitness to drive and the safety of older drivers. Many older adults depend greatly on their personal vehicle for transportation and suffer a marked loss of quality of life when, as a consequence of no longer being able or permitted to drive, their mobility becomes significantly restricted. The reasons for the deterioration of driving performance that occur during the aging process are multi-factorial and a great deal of research has focused on the identification of those factors. Nevertheless, some studies incorporating training programs have tried, with some success, to improve the driving-related abilities of older drivers. It has been demonstrated that physical activity can promote several skills that are associated with driving performance in older drivers. Few studies, though, have conducted exercise interventions among older drivers
\end{abstract}

\footnotetext{
J. Marmeleira $(\bowtie) \cdot$ P. Vogelaere

Department of Sport and Health,

University of Évora,

Pavilhão Gimnodesportivo,

Prolongamento da Rua de Monsaraz, 14,

7000-727 Évora, Portugal

e-mail: jmarmel@uevora.pt

P. Vogelaere

e-mail: pvogelaere@uevora.pt

M. Godinho

Faculty of Human Kinetics,

Technical University of Lisbon,

Estrada da Costa,

1495-688 Cruz Quebrada, Portugal

e-mail: mgodinho@fmh.utl.pt
}

intended to enhance their driving-related abilities and promote road safety. In this context, the purpose of this work consists of examining the perceptual, cognitive, health, and physical factors related to fitness to drive in older adults and identifying possible strategies that can enhance their driving-related abilities. Moreover, potential mechanisms underlying the relationship among physical activity, driving ability, and road safety are discussed.

Keywords Driving · Aging · Physical activity

\section{Introduction}

Considering the data regarding road accidents and the demographic evolution, namely the increase in the older population, researchers and public health authorities are showing more interest in issues associated with fitness and safety to drive in older adults. In fact, older adults have become a larger part of the driving population and will continue to do so as "baby boomers" reach retirement age $[58,72]$.

In developed countries, the older population has become more dependent on their private cars and it seems very unlikely that other transportation alternatives can fully provide the level of mobility that older adults need [92, 93]. Driving is essential for older adults to continue their engagement in civic, social, and community life, and to remain involved in the human interactions necessary for health, well-being, and quality of life [26, 117]. Driving cessation has been linked to decreased participation in out-of-home activities and increased depressive symptoms $[31,66]$.

The number of crashes per distance traveled is higher in elderly drivers than in all other groups of drivers [38, 84]. 
Older drivers also have a high risk of injury or death in traffic accidents $[55,73]$ and are commonly found to be 'at fault' in crashes [84]. There is strong evidence that older drivers will make up a substantially larger proportion of drivers involved in fatal crashes in the next few decades. This is due to the proportional increase in the older population, the increment of the driving licensure rates, and higher annual distances covered [58, 72, 119].

Nevertheless, the crash rates for older drivers are lower per capita than for drivers of other ages since they drive shorter distances and are less often licensed to drive [58, 119]. Functional declines associated with aging appear to prompt some drivers to voluntarily change their driving habits [57, 104]; many older drivers report limiting their driving, especially to avoid complex driving situations such as peak travel times, night-time driving, and adverse weather conditions $[9,46]$. However, because older occupants of vehicles comprise a large proportion of future deaths in motor vehicle crashes, public health efforts to reduce their morbidity and mortality should be pursued [58].

The most widely recommended road safety strategy for older drivers relates to the restriction of their driving licenses [113]. Nevertheless, this type of countermeasure needs to be carefully evaluated due to the negative consequences related to the restriction of elderly mobility, and increased emphasis should be placed on effective methods of protecting older drivers and passengers when they travel in vehicles [58].

Diverse perceptive, cognitive, and motor factors have been associated with driving difficulties and crash incidence in older adults. In a literature review, Anstey et al. [5] reported that measures of attention, reaction time, memory, executive function, mental status, visual function, and physical function were associated with driving outcome measures. Health status (e.g., cardiovascular illnesses, diabetes mellitus, state of depression, and dementia) has also been linked with the occurrence of crashes in older drivers $[2,73,96]$.

Aging is associated with a decline in several cognitive skills and brain functions [17, 111] which can result in driving difficulties. For example, a decline in information processing speed, loss of efficiency in acquiring new information, cognitive inflexibility, a decline in executive functioning, a reduction in attentional resources, and a reduction in working memory function have been demonstrated [10, 111].

Interestingly, the practice of physical activities has a positive effect on perceptive, cognitive, and physical abilities as well as on health factors that are considered important for driving performance and safety among older adults. For instance, older people with a good physical fitness level show greater efficiency in information processing $[29,52]$, enhancement of attention capacity in dual- task situations [40], and better performance on tasks that require visual-spatial processing [102]. The effects of physical activity on cognitive factors seem to be more accentuated for tasks that request greater attention resources $[22,29,116]$. Furthermore, physical activity is a key factor for healthful aging $[4,120]$.

In this context, the purpose of this review is to examine the perceptual, cognitive, health, and physical factors that are related to fitness to drive in older adults and at the same time to identify possible strategies that could enhance their driving-related abilities. Moreover, we intend to identify and analyse the potential mechanisms that could support and promote a relationship between physical activity, driving ability, and road safety.

\section{Visual attention}

Visual attention is a cognitive function involving search, selection, and switching that plays an important role in driving [88]. Changes in visual attention often occur in older adults, leading to marked difficulties in driving $[5,8$, 30, 79].

Standard clinical measures of visual function tests have demonstrated little sensitivity for identifying risky drivers $[7,78]$. Conversely, a computer-based test- the UFOV ${ }^{\circledR}$ test-supported by the concept of useful field of view (UFOV), was identified as a valid and reliable index of driving performance and safety in older adults [5]. The concept of UFOV was introduced by Sanders [98], who used the term "functional visual field" to indicate the visual area over which information can be acquired in a brief glance without eye or head movements. The UFOV ${ }^{\circledR}$ test combines the evaluation of visual processing speed and selective and divided visual attention, and evidence has shown that its performance also relies on higher-order cognitive abilities as well as visual sensory function [8].

The possible effects of age on the UFOV have been examined. Ball et al. [12] found slight differences in visual attention performance between young (22-33 years old) and middle-aged individuals (40-49 years old) but large performance differences between both groups and a sample of elderly individuals (60-75 years old). Other authors have found similar results, suggesting that critical changes in the UFOV occur around 60 years of age [63, 100]. However, a recent investigation conducted in a driving simulator reported that middle-aged drivers (46-57 years old) already showed a substantial decrease on the UFOV when their performance was compared with that of younger drivers (21-34 years old) [91]. Sekuler et al. [101] concluded that the UFOV size does not decrease with age but that older people process the received information less efficiently within the UFOV. These changes appear to occur gradually 
during the normal lifespan. Such an interpretation is quite different from that originally suggested by Ball et al. [12], in which UFOV is constricted in older people.

A study on the relationship between exercise and visual attention have shown that 10 weeks of aerobic exercise (aquatic training) induced a beneficial influence on attention in older adults during dual-task processing [40]. Roth et al. [94] concluded that individuals who regularly engaged in physical activity had significantly better $\mathrm{UFOV}^{\circledR}$ scores than less active individuals. Recently, it was reported that elderly individuals who have expertise in orienteering activities have developed attentional skills that outweigh the age-related changes of visual attentional focusing [82]. Marmeleira et al. [62] showed that an specific exercise program that incorporated open skills and demanding perceptive activities was successful in improving visual attention in a group of older drivers (60 to 81 years old). It has been suggested that participation in exercise programs can induce brain-vascular and neurochemical benefits that allow the preservation of attention function in the elderly [21,27].

Driver distraction is another critical factor for driving safety and is closely associated with visual attention. It can be defined as the momentary or transient redirection of attention from the task of driving to a thought, object, activity, event, or person and represents approximately $24 \%$ of the human causal factor contribution to all accidents [18]. It is known that secondary tasks interfere with driving performance, affecting visual search, detection of hazards, and detection of changes in the driving scene [86]. Dualtask changes are more frequently observed in older than in younger adults $[16,19]$.

The research regarding driving and distraction has been focused essentially on the negative effects of using cell phones. Older drivers are more adversely affected by using a cell phone than younger drivers $[19,39]$. On average, reaction time increases by $0.23 \mathrm{~s}$ with cell phone usage, but for older drivers this increase can reach $0.46 \mathrm{~s}$ [18].

It is promising that dual-task deficits can be reduced, either by specific cognitive training [16] or physical exercise [40,62].

\section{Executive function}

Executive function consists of a set of higher-order cognitive abilities primarily associated with the frontal and prefrontal structures of the brain; it involves skills such as planning, organizing information, inhibiting responses, and orchestrating mental resources [11]. This set of skills subserves goal-directed, future-oriented behavior and does not become automatic over time, requiring constant mediation by a central executor [23].
Executive function is necessary to plan and coordinate sensorimotor and cognitive responses to complex driving situations and requires adequate working memory resources so that relevant information may be held in mind during the decision-making process [5]. Given that the types of crashes in which older adults are involved often occur in complex traffic situations such as intersections [71, 72], it is reasonable to hypothesize that difficulties occur at the level of executive function (i.e., the planning and decisionmaking part of the driving task) [5].

Daigneault et al. [24] found that drivers who had accidents during the previous 5 years performed poorly on measures of executive functioning. Another study demonstrated that older drivers with mild dementia showed a positive correlation between the results of an on-road driving test and the performance on executive function control and visual attention tests [118]. Recently, it was reported that executive dysfunction may be an important contributor to pedal errors among older drivers [33] and that poor planning ability is independently associated with driving difficulties [30].

In the last several years, relevant investigations have indicated that the frontal neural system (region that mediates executive function) is the primary locus in which aging-related cognitive changes are found and where physical fitness appears to exert its greatest influence [17, $23,52]$. In older adults, it has been suggested that aerobic fitness has a larger impact on tasks that require controlled and effortful processing compared with tasks that are executed using automatic processing [22, 29, 116]. Furthermore, it was found that tasks pertaining to fluid intelligence are more sensitive to physical fitness than those corresponding to crystallized intelligence [21]; executive function and fluid intelligence are related, involving many of the same cognitive processes [35].

Colcombe and Kramer [23], in a meta-analytic review of fitness intervention studies conducted from 1966 through 2001, found a clear and significant effect of aerobic fitness training in the cognitive function of older adults. The fitness effects were more patent in tasks that involved executive control processes. Those authors also found that participation in relatively brief training programs (13 months) provided at least as much benefit as moderate training (4-6 months), but not quite as much as long-term training programs $(6+$ months).

\section{Behavioral speed}

Slowing of motor performance during human aging is well demonstrated in clinical observation [75, 103, 109, 111]. Behavioral speed consists of two major components: reaction time to environmental stimuli and speed of 
execution [111]. Evidence suggests that central mechanisms are fundamental in the aging-related slowing of the speed of response and that the sensory and motor factors have only slight effects on that phenomenon [97].

The effect of age on reaction time is more pronounced in tasks that have high levels of complexity $[25,56,112]$. Reaction time also becomes more variable with age [25, 43]. It has been observed that, although vehicle operations become relatively more automatic with experience, driving is a complex and interactive task involving a variety of skills, requiring the ability to make appropriate and timely decisions $[39,76]$. Actually, older drivers are frequently involved in crashes that occur in complex traffic situations; for example, older drivers are over-represented in crashes at intersections, in crashes involving failure to yield the right of way, and in crashes occurring while turning and changing lanes $[7,71,72]$.

McKnight and McKnight [74] found a moderate correlation between reaction time and on-road driving performance, with larger associations found for complex reaction times than for simple ones. Green [36] suggested that a behavioral-slowing trend occurs with aging, which is reflected in greater brake reaction times. A recent dual-task study demonstrated that performing mental calculations while driving markedly increased the average reaction time of elderly drivers [59].

A study of 1,425 older drivers (between the ages of 67 and 87 years) showed that age, gender, and cognition are predictive factors for the total brake reaction time [121]. The decline in reaction time was associated with low scores in cognitive factors and visual field deficits. The increase in response time was related to having three or more physical complaints related to legs and feet and poorer vision search. This study concluded that drivers in good physical condition may perform poorly on brake reaction tests if their vision or cognition is compromised.

Research regarding physical activity has reported better performances on simple and choice reaction tasks among active older adults compared with inactive subjects $[4,27$, 110]. In the driving-related literature, behavioral speed was studied by Hancock et al. [39] in young athletes on a braking task experiment. Curiously, these authors did not find any advantage of skilled sport practitioners in comparison with non-practitioners in measures of reaction, movement, and response time; they suggested that the advantage of sports participation is not the behavioral speed but the ability to produce the desirable performance in context. Recently, Matos and Godinho [70] reported that a specific perceptual-motor training program could enhance the useful field of view and the peripheral reaction time in novice drivers, suggesting that exercise that requires demanding information processing, and for which event perception is crucial, could be positively transferred to driving situations. Moreover, Marmeleira et al. [62] concluded that a type of exercise focusing not only physiological systems but also perceptive and cognitive mechanisms was successful in improving simple reaction in single- and dual-task condition among older drivers.

\section{Health status}

Several health conditions have been associated with the involvement of older drivers in car crashes, namely heart disease, stroke, arthritis, diabetes, a history of myocardial infarction, poor vision, myopia, sleep onset insomnia, frequent tiredness, anxiety, or feeling depressed [73, 96, 105]. The use of non-steroidal anti-inflammatory drugs, antidepressants, benzodiazepines, angiotensin-converting enzyme inhibitors, hypnotic medications, and anticoagulants was also associated with an increased risk of crash involvement [73, 96, 105].

A large body of laboratory- and population-based studies has documented many health and fitness benefits associated with physical activity, such as improved physiologic, metabolic, and psychological parameters, as well as a decreased risk for many chronic diseases and premature mortality $[4,48,120]$. Given the link between health and driving performance, the positive influence of physical activity on health could positively influence driving performance in older adults.

The problems associated with dementia are particularly relevant to driving $[1,50]$. Dementia is a syndrome that affects essential cognitive functions like memory, judgment, and psychomotor abilities [44]. Alzheimer's disease is the most common form of dementia [87]. Compared to most of the general driving population, drivers with dementia are at an increased risk for unsafe motor vehicle operation and crashes [2, 32, 114]. Friedland et al. [34] reported that 77\% of patients with dementia of the Alzheimer's type showed deterioration in driving performance and that $63 \%$ of those patients stopped driving; however, only $42 \%$ of the patients with dementia who stopped driving did so before a crash occurred. Many individuals with dementia continue to drive even after the onset of symptoms [1].

The risk of dementia, cognitive impairment, cognitive decline, and Alzheimer's disease is lower among persons engaging in high levels of physical activity, compared with those performing low levels of physical activity [89]. A study conducted in the USA with 3,375 men and women, aged 65 years or older, showed that participants in the highest quartile of physical energy expenditure had a relative risk of dementia of 0.85 compared with those in the lowest quartile [83]. 
Since driving is an intense visual task, it has long been thought that visual impairment should be associated with crash risk [95]. Frequently, satisfactory performance on a vision test (often only a visual acuity test) is required to obtain a driver's license [46]. Most aspects of visual function decline after the age of 50 years [45]. Studies have found that drivers with changes in visual acuity, glare sensitivity, binocular visual field, or contrast sensitivity have a greater crash risk [37, 42, 81, 95]. However, most studies have shown weak or no association between crash risk and visual function either in the general driving population or among older drivers [5, 20, 46, 78]. Overall, the scientific literature suggests that visual tests used in isolation are not strong predictors of crash involvement because they do not tap into the visual and cognitive complexity of the driving task $[5,7,78]$.

\section{Physical functioning}

A history of falls and poor mobility have been found to be associated with driving difficulties or crash involvement in older drivers [13, 57, 65, 106, 107]. Poor neck rotation was also found to be related to an increased risk of crashing [69]. Marottoli and Drickamer [67] considered that the key elements of motor ability for older drivers include strength, range of motion of the extremities, trunk and neck mobility, and proprioception. However, they noted that limited information is available on the specific level of motor ability necessary for driving.

Previous investigations have explored the potential link between physical training and driving-related abilities. Marottoli et al. [64] demonstrated the possibility of maintaining or enhancing driving performance among physically impaired older drivers ( $>70$ years of age) using a safe, well-tolerated multicomponent physical conditioning program. The intervention protocol targeted axial/extremity range of motion (e.g., cervical and trunk rotation, ankle dorsiflexion, and plantarflexion), upper extremity coordination/dexterity, hand strength, gait, and foot abnormalities.

A randomized control trial reported that an 8-week range-of-motion exercise training program successfully improved older drivers' shoulder flexibility and trunk rotation as well as their scores on the variable "observing" (percentage of appropriate responses in observing to the rear, side, and rear quarter, involving use of mirrors, turning the head, and looking over the shoulder) [77]. Tuokko et al. [115] found that older adults with lower physical activity levels had evident driving difficulties involving the spine and lower body. They suggested that physical activity focused on the improvement of spinal flexibility could enhance specific aspects of driving performance, such as turning to check for traffic or operating a seat belt. Those authors considered it to be encouraging that the most frequently reported symptoms were located in areas highly amenable to modification and pointed out that most of the older drivers expressed a willingness to engage in exercise programs if an association between physical fitness and driving could be demonstrated.

\section{Speed perception}

Speed perception has been identified as an important ability for safe driving [41, 61, 85]. This concept is frequently known as time-to-contact (TTC) [60]. Despite some methodological differences, studies about driving concerning TTC are linked with the visual perception of approaching vehicles. One of the main differences in methodology is related to the fact that the observer is stationary or in motion. TTC involves primarily the local transformation of optical information through changes in the size of the image on the retina $[41,60]$.

A high proportion of accidents involving older drivers occur at intersections when entering the traffic or crossing a main road [71]. In those situations, it is very important to correctly perceive speed, distance, and "time away" of the approaching vehicle [41, 72]. Previous findings have indicated that older drivers underestimate the TTC of other vehicles to a greater degree than younger drivers $[54,99]$.

It is a common idea that less accuracy or more variability in the TTC perception of older drivers, combined with factors such as longer road crossing times, could explain their tendency to be more conservative than young drivers when deciding to enter traffic, accepting larger gaps, and by this means, trying to reduce the probability of a traffic accident $[49,108]$. Relative underestimation of TTC might reflect some loss of perception capability. On the other hand, it could be beneficial for promoting a more preventive behavior, such as encouraging drivers to choose larger gaps between successive oncoming vehicles [41].

Female drivers tend to exhibit larger TTC underestimations than male drivers [54, 99]. Women often evaluate their driving capabilities more negatively than men, reporting more driving difficulties [30], which could lead to more cautious behaviour. A review of this issue concluded that, after controlling for driving exposure, women were less likely to be involved in vehicle crashes than men, and gender differences were greater among young and inexperienced drivers [28].

In the driving-related literature, we have only found one study [62] that examined the effects of exercise on speed perception in older drivers. After 12 weeks of exercise, there was no evidence of any positive effect on speed perception. 


\section{Training programs for older drivers}

A great deal of research has focused on elderly drivers' crash-involvement patterns, but not on the development and evaluation of methods allowing the enhancement of their driving-related abilities [53]. However, some scientific research has examined the effectiveness of retraining programs for older drivers using interventions in areas such as education, visual attention, or physical functioning. In-class and on-road education programs may help older drivers to improve their knowledge of safe driving practices and actual driving performances $[15,68]$. However, not all education interventions have been found to improve driving performance in older drivers [14], and there is no evidence that post-license educational programs are effective in preventing road traffic crashes [15, 47].

Other methods have been used to enhance drivingrelated abilities in older adults. It has been reported that visual attention retraining programs using the UFOV ${ }^{\circledR}$ software resulted in fewer dangerous maneuvers during an open-road driving evaluation $[6,90]$ and that simulator-training was capable of enhancing driving performance in older adults $[3,90]$. As already described, some studies have also demonstrated that programs focused on physical mobility retraining could enhance driving skills $[68,77]$.

Some interventions for older drivers have focused only on high-risk groups. Owsley et al. [80] reported that an educational program promoting safe-driving strategies among visually impaired older drivers did not enhance driving safety. Kooijman et al. [51], in a study among drivers with visual field defects, reported that a compensatory viewing training (laboratory and mobility training, including driving instruction) improved the driving performance in an on-road test.

Interestingly, research among older drivers has not consistently explored the possible benefits of multifaceted intervention programs that integrates educational, motor, sensory, and cognitive components; all of those factors have individually been shown to be reasonably effective in improving driving behavior [53]. It is promising that, in a recent experimental study, a specific exercise program planned to stress perceptive, cognitive, and physical abilities was successful in improving several abilities (behavioral speed, visual attention, and psychomotor performance) considered critical for driving performance and safety among older adults [62]. Given that the task of driving involves a complex interplay of factors, more specific intervention programs capable of targeting several important domains are needed.

\section{Summary}

The elderly represent the fastest growing driving population, and despite their lower crash rates per capita compared with drivers of other ages, they are believed to represent a high risk to road safety given their high crash rate per distance traveled.

Many older adults depend greatly on their personal automobile for transportation. They suffer a marked loss of quality of life when their mobility becomes significantly restricted, as a result of being no longer able or permitted to drive.

The reasons for the deterioration in driving performance occur along the aging process and are multi-factorial. A great deal of safety research on older drivers has focused on the identification of these factors. Some training programs directed to factors like visual attention, physical mobility, and driving education have improved the driving performance of older drivers.

It has been demonstrated that physical activity is capable of enhancing several perceptive, cognitive, physical, and health factors associated with driving performance in older drivers. However, few studies have conducted exercise interventions among older drivers that were intended to enhance their driving-related abilities and promote road safety.

Future research should explore the potential role of physical activity in preventing the deterioration or enhancing the driving-related abilities of older adults.

\section{References}

1. Adler G, Kuskowski M (2003) Driving cessation in older men with dementia. Alzheimer Dis Assoc Disord 17:68-71, doi:10.1097/00002093-200304000-00003

2. Adler G, Rottunda S, Dysken M (2005) The older driver with dementia: an updated literature review. J Safety Res 36:399-407, doi:10.1016/j.jsr.2005.07.005

3. Akinwuntan AE, De Weerdt W, Feys H, Pauwels J, Baten G, Arno P, Kiekens C (2005) Effect of simulator training on driving after stroke: a randomized controlled trial. Neurology 65:843850, doi:10.1212/01.wnl.0000171749.71919.fa

4. American College of Sports Medicine (1998) Position stand: exercise and physical activity for older adults. Med Sci Sports Exerc 30:992-1008, doi:10.1097/00005768-199806000-00033

5. Anstey KJ, Wood J, Lord S, Walker JG (2005) Cognitive, sensory and physical factors enabling driving safety in older adults. Clin Psychol Rev 25:45-65, doi:10.1016/j. cpr.2004.07.008

6. Ball K (1997) Enhancing mobility in the elderly: attentional interventions for driving. In: Dollinger SMC, DiLalla LF (eds) Assessment and intervention issues across the life span. Erlbaum, Mahwah

7. Ball K, Owsley C (1993) The useful field of view test: a new technique for evaluating age-related declines in visual function. J Am Optom Assoc 64:71-79 
8. Ball K, Owsley C, Sloane ME, Roenker DL, Bruni JR (1993) Visual attention problems as a predictor of vehicle crashes in older drivers. Invest Ophthalmol Vis Sci 34:3110-3123

9. Ball K, Owsley C, Stalvey B, Roenker DL, Sloane ME, Graves M (1998) Driving avoidance and functional impairment in older drivers. Accid Anal Prev 30:313-322, doi:10.1016/S0001-4575 (97)00102-4

10. Ball K, Vance D, Edwards J, Wadley V (2004) Aging and the brain. In: Rizzo M, Eslinger P (eds) Principles and practices of behavioral neurology and neuropsychology. Saunders, Elsevier, Philadelphia, pp 795-809

11. Ball K, Wadley V, Vance D, Edwards J (2004) Cognitive skills: training, maintenance, and daily usage. In: Speilberg C (ed) Encyclopedia of applied psychology. Elsevier, New York, pp 387-392

12. Ball KK, Beard BL, Roenker DL, Miller RL, Griggs DS (1988) Age and visual search: expanding the useful field of view. J Opt Soc Am A 5:2210-2219, doi:10.1364/JOSAA.5.002210

13. Ball KK, Roenker DL, Wadley VG, Edwards JD, Roth DL, McGwin G Jr, Raleigh R, Joyce JJ, Cissell GM, Dube T (2006) Can high-risk older drivers be identified through performancebased measures in a Department of Motor Vehicles setting? J Am Geriatr Soc 54:77-84, doi:10.1111/j.1532-5415.2005.00568.x

14. Bedard M, Isherwood I, Moore E, Gibbons C, Lindstrom W (2004) Evaluation of a re-training program for older drivers. Can J Public Health 95:295-298

15. Bedard M, Porter MM, Marshall S, Isherwood I, Riendeau J, Weaver B, Tuokko H, Molnar F, Miller-Polgar J (2008) The combination of two training approaches to improve older adults' driving safety. Traffic Inj Prev 9:70-76, doi:10.1080/ 15389580701670705

16. Bherer L, Kramer AF, Peterson MS, Colcombe S, Erickson K, Becic E (2005) Training effects on dual-task performance: are there age-related differences in plasticity of attentional control. Psychol Aging 20:695-709, doi:10.1037/0882-7974.20.4.695

17. Bixby WR, Spalding TW, Haufler AJ, Deeny SP, Mahlow PT, Zimmerman JB, Hatfield BD (2007) The unique relation of physical activity to executive function in older men and women. Med Sci Sports Exerc 39:1408-1416, doi:10.1249/ mss.0b013e31806ad708

18. Caird J, Dewar R (2007) Driver distraction. In: Dewar R, Olson $\mathrm{P}$ (eds) Human factors in traffic safety. Laywers \& Judges, Tucson, pp 195-222

19. Chaparro A, Wood JM, Carberry T (2005) Effects of age and auditory and visual dual tasks on closed-road driving performance. Optom Vis Sci 82:747-754, doi:10.1097/01. opx.0000174724.74957.45

20. Charman WN (1997) Vision and driving - a literature review and commentary. Ophthalmic Physiol Opt 17:371-391

21. Chodzko-Zajko WJ (1991) Physical fitness, cognitive performance, and aging. Med Sci Sports Exerc 23:868-872, doi:10.1249/00005768-199107000-00016

22. Chodzko-Zajko WJ, Moore KA (1994) Physical fitness and cognitive functioning in aging. Exerc Sport Sci Rev 22:195-220, doi:10.1249/00003677-199401000-00009

23. Colcombe S, Kramer AF (2003) Fitness effects on the cognitive function of older adults: a meta-analytic study. Psychol Sci 14:125-130, doi:10.1111/1467-9280.t01-1-01430

24. Daigneault G, Joly P, Frigon JY (2002) Executive functions in the evaluation of accident risk of older drivers. J Clin Exp Neuropsychol 24:221-238, doi:10.1076/jcen.24.2.221.993

25. Der G, Deary IJ (2006) Age and sex differences in reaction time in adulthood: results from the United Kingdom Health and Lifestyle Survey. Psychol Aging 21:62-73, doi:10.1037/ 0882-7974.21.1.62
26. Dickerson AE, Molnar LJ, Eby DW, Adler G, Bedard M, BergWeger M, Classen S, Foley D, Horowitz A, Kerschner H, Page O, Silverstein NM, Staplin L, Trujillo L (2007) Transportation and aging: a research agenda for advancing safe mobility. Gerontologist 47:578-590

27. Dustman R, Emmerson R, Schearer D (1994) Physical activity, age, and cognitive neuropsychological function. J Aging Phys Act 2:143-181

28. Elander J, West R, French D (1993) Behavioral correlates of individual differences in road-traffic crash risk: an examination method and findings. Psychol Bull 113:279-294, doi:10.1037/ 0033-2909.113.2.279

29. Etnier J, Salazar W, Landers D, Petruzzello S, Han M, Novell P (1997) The influence of physical fitness and exercise upon cognitive functioning: a meta analysis. J Sport Exerc Psychol 19:249-277

30. Ferreira I, Marmeleira J, Godinho M, Simões M (2007) Cognitive factors and gender related to self-reported difficulties in older drivers. In: Fourth International Driving Symposium on Human Factors in Driver Assessment, Training and Vehicle Design. Stevenson, Washington, p 511-518

31. Fonda SJ, Wallace RB, Herzog AR (2001) Changes in driving patterns and worsening depressive symptoms among older adults. J Gerontol B Psychol Sci Soc Sci 56:S343-S351

32. Fox GK, Bowden SC, Bashford GM, Smith DS (1997) Alzheimer's disease and driving: prediction and assessment of driving performance. J Am Geriatr Soc 45:949-953

33. Freund B, Colgrove LA, Petrakos D, McLeod R (2008) In my car the brake is on the right: pedal errors among older drivers. Accid Anal Prev 40:403-409, doi:10.1016/j.aap.2007.07.012

34. Friedland RP, Koss E, Kumar A, Gaine S, Metzler D, Haxby JV, Moore A (1988) Motor vehicle crashes in dementia of the Alzheimer type. Ann Neurol 24:782-786, doi:10.1002/ ana. 410240613

35. Goldstein FC, Green RC (1995) Assessment of problem solving and executive functions. In: Mapou RL, Spector J (eds) Clinical neuropsychological assessment: a cognitive approach. Plenum, New York, pp 49-81

36. Green M (2000) How long does it take to stop? Methodological analysis of driver perception-brake times. Transp Hum Factors 2:195-216, doi:10.1207/STHF0203 1

37. Gresset JA, Meyer FM (1994) Risk of accidents among elderly car drivers with visual acuity equal to $6 / 12$ or $6 / 15$ and lack of binocular vision. Ophthalmic Physiol Opt 14:33-37, doi:10.1111/j.1475-1313.1994.tb00553.x

38. Guerrier JH, Manivannan P, Nair SN (1999) The role of working memory, field dependence, visual search, and reaction time in the left turn performance of older female drivers. Appl Ergon 30:109-119, doi:10.1016/S0003-6870(98)00017-9

39. Hancock PA, Lesch M, Simmons L (2003) The distraction effects of phone use during a crucial driving maneuver. Accid Anal Prev 35:501-514, doi:10.1016/S0001-4575(02) 00028-3

40. Hawkins HL, Kramer AF, Capaldi D (1992) Aging, exercise, and attention. Psychol Aging 7:643-653, doi:10.1037/08827974.7.4.643

41. Hesketh B, Godley ST (2002) A comparison of time estimations in driving with target-only in motion, self-only in motion, and self-and-target in motion. Ecol Psychol 14:111-125, doi:10.1207/S15326969ECO1403_1

42. Hofstetter HW (1976) Visual acuity and highway accidents. J Am Optom Assoc 47:887-893

43. Hultsch DF, MacDonald SW, Dixon RA (2002) Variability in reaction time performance of younger and older adults. $J$ Gerontol B Psychol Sci Soc Sci 57:101-115 
44. Johansson K, Lundberg C (1997) The 1994 International consensus conference on Dementia and Driving: a brief report. Swedish National Road Administration. Alzheimer Dis Assoc Disord 11(Suppl 1):62-69, doi:10.1097/00002093-19970600100013

45. Johnson MA, Choy D (1987) On the definition of age-related norms for visual function testing. Appl Opt 26:1449-1454

46. Keeffe JE, Jin CF, Weih LM, McCarty CA, Taylor HR (2002) Vision impairment and older drivers: who's driving? $\mathrm{Br} \mathrm{J}$ Ophthalmol 86:1118-1121, doi:10.1136/bjo.86.10.1118

47. Ker K, Roberts I, Collier T, Beyer F, Bunn F, Frost C (2005) Post-licence driver education for the prevention of road traffic crashes: a systematic review of randomised controlled trials. Accid Anal Prev 37:305-313, doi:10.1016/j.aap.2004.09.004

48. Kesaniemi YK, Danforth E Jr, Jensen MD, Kopelman PG, Lefebvre P, Reeder BA (2001) Dose-response issues concerning physical activity and health: an evidence-based symposium. Med Sci Sports Exerc 33:S351-S358, doi:10.1097/00005768200106001-00003

49. Keskinen E, Ota H, Katila A (1998) Older drivers fail in intersections: speed discrepancies between older and younger male drivers. Accid Anal Prev 30:323-330, doi:10.1016/S00014575(97)00113-9

50. Klavora P, Heslegrave R (2002) Senior drivers: an overview of problems and intervention strategies. J Aging Phys Act 10:322335

51. Kooijman C, Brouwer WH, Coeckelbergh TR, Tant ML, Cornelissen FW, Bredewoud RA, Melis-Dankers BJ (2004) Compensatory viewing training improves practical fitness to drive of subjects with impaired vision. Vis Impairment Res 6:127, doi:10.1080/13882350390486965

52. Kramer AF, Colcombe S, Erickson K, Belopolsky A, McAuley E, Cohen NJ, Webb A, Jerome GJ, Marquez DX, Wszalek TM (2002) Effects of aerobic fitness training on human cortical function: a proposal. J Mol Neurosci 19:227-231, doi:10.1007/ s12031-002-0038-y

53. Kua A, Korner-Bitensky N, Desrosiers J, Man-Son-Hing M, Marshall S (2007) Older driver retraining: a systematic review of evidence of effectiveness. J Safety Res 38:81-90, doi:10.1016/j. jsr.2007.01.002

54. Leung S, Starmer G (2005) Gap acceptance and risk-taking by young and mature drivers, both sober and alcohol-intoxicated, in a simulated driving task. Accid Anal Prev 37:1056-1065, doi:10.1016/j.aap.2005.06.004

55. Li G, Braver ER, Chen LH (2003) Fragility versus excessive crash involvement as determinants of high death rates per vehicle-mile of travel among older drivers. Accid Anal Prev 35:227-235, doi:10.1016/S0001-4575(01)00107-5

56. Luchies CW, Schiffman J, Richards LG, Thompson MR, Bazuin D, DeYoung AJ (2002) Effects of age, step direction, and reaction condition on the ability to step quickly. J Gerontol A Biol Sci Med Sci 57:M246-M249

57. Lyman JM, McGwin G Jr, Sims RV (2001) Factors related to driving difficulty and habits in older drivers. Accid Anal Prev 33:413-421, doi:10.1016/S0001-4575(00)00055-5

58. Lyman S, Ferguson SA, Braver ER, Williams AF (2002) Older driver involvements in police reported crashes and fatal crashes: trends and projections. Inj Prev 8:116-120, doi:10.1136/ ip. 8.2 .116

59. Makishita H, Matsunaga K (2008) Differences of drivers' reaction times according to age and mental workload. Accid Anal Prev 40:567-575, doi:10.1016/j.aap.2007.08.012

60. Manser MP, Hancock PA (1996) Influence of approach angle on estimates of time to-contact. Ecol Psychol 8:71-99, doi:10.1207/ s15326969eco0801_4
61. Marmeleira J, Ferreira I, Godinho M, Fernandes O (2007) Time to arrival and useful field of view: associations with reported driving difficulties among older adults. In: Fourth International Driving Symposium on Human Factors in Driver Assessment, Training and Vehicle Design., Stevenson, Washington, $\mathrm{p}$ 91-97

62. Marmeleira J, Godinho M, Fernandes O (2008) The effects of an exercise program on several abilities associated with driving performance in older adults. Accid Anal Prev 41(1):90-97, doi:10.1016/j.aap.2008.09.008

63. Marmeleira J, Godinho M, Malarranha F, Fernandes O (2009) Effects of age in useful field of view and time-to-arrival. Adv Transp Stud An Int J (in press)

64. Marottoli RA, Allore H, Araujo KL, Iannone LP, Acampora D, Gottschalk M, Charpentier P, Kasl S, Peduzzi P (2007) A randomized trial of a physical conditioning program to enhance the driving performance of older persons. J Gen Intern Med 22:590-597, doi:10.1007/s11606-007-0134-3

65. Marottoli RA, Cooney LM Jr, Wagner R, Doucette J, Tinetti ME (1994) Predictors of automobile crashes and moving violations among elderly drivers. Ann Intern Med 121:842-846

66. Marottoli RA, de Leon CFM, Glass TA, Williams CS, Cooney LM Jr, Berkman LF (2000) Consequences of driving cessation: decreased out-of-home activity levels. J Gerontol B Psychol Sci Soc Sci 55:S334-S340

67. Marottoli RA, Drickamer MA (1993) Psychomotor mobility and the elderly driver. Clin Geriatr Med 9:403-411

68. Marottoli RA, Ness PH, Araujo KL, Iannone LP, Acampora D, Charpentier P, Peduzzi P (2007) A randomized trial of an education program to enhance older driver performance. J Gerontol A Biol Sci Med Sci 62:1113-1119

69. Marottoli RA, Richardson ED, Stowe MH, Miller EG, Brass LM, Cooney LM Jr, Tinetti ME (1998) Development of a test battery to identify older drivers at risk for self-reported adverse driving events. J Am Geriatr Soc 46:562-568

70. Matos R, Godinho M (2007) Useful field of vision and peripheral reaction time in novice drivers: transfer to a real driving situation after a perceptual-motor training program. Adv Transp Stud An Int J (in press)

71. Mayhew DR, Simpson HM, Ferguson SA (2006) Collisions involving senior drivers: high-risk conditions and locations. Traffic Inj Prev 7:117-124, doi:10.1080/15389580600636724

72. McGwin G Jr, Brown DB (1999) Characteristics of traffic crashes among young, middle-aged, and older drivers. Accid Anal Prev 31:181-198, doi:10.1016/S0001-4575(98)00061-X

73. McGwin G Jr, Sims RV, Pulley L, Roseman JM (2000) Relations among chronic medical conditions, medications, and automobile crashes in the elderly: a population-based case-control study. Am J Epidemiol 152:424-431, doi:10.1093/aje/152.5.424

74. McKnight AJ, McKnight AS (1999) Multivariate analysis of age-related driver ability and performance deficits. Accid Anal Prev 31:445-454, doi:10.1016/S0001-4575(98)00082-7

75. Nicoletti G, Arabia G, Pugliese P, Torchia G, Pucci F, Gambardella A, Quattrone A, Zappia M (2005) Movement time and aging: a normative study in healthy subjects with the "Movement Time Analyzer". Aging Clin Exp Res 17:207-210

76. Olson P, Dewar R (2007) Introduction. In: Dewar R, Olson P (eds) Human factors in traffic safety. Lawyers \& Judges, Tucson, pp 1-7

77. Ostrow AC, Shaffron P, McPherson K (1992) The effects of a joint range-of-motion physical fitness training program on the automobile driving skills of older adults. J Safety Res 23:207219, doi:10.1016/0022-4375(92)90003-R

78. Owsley C, Ball K, McGwin G Jr, Sloane ME, Roenker DL, White MF, Overley ET (1998) Visual processing impairment and 
risk of motor vehicle crash among older adults. JAMA 279:1083-1088, doi:10.1001/jama.279.14.1083

79. Owsley C, Ball K, Sloane ME, Roenker DL, Bruni JR (1991) Visual/cognitive correlates of vehicle accidents in older drivers. Psychol Aging 6:403-415, doi:10.1037/0882-7974.6.3.403

80. Owsley C, McGwin G Jr, Phillips JM, McNeal SF, Stalvey BT (2004) Impact of an educational program on the safety of highrisk, visually impaired, older drivers. Am J Prev Med 26:222229, doi:10.1016/j.amepre.2003.12.005

81. Owsley C, Stalvey BT, Wells J, Sloane ME, McGwin G Jr (2001) Visual risk factors for crash involvement in older drivers with cataract. Arch Ophthalmol 119:881-887

82. Pesce C, Cereatti L, Casella R, Baldari C, Capranica L (2007) Preservation of visual attention in older expert orienteers at rest and under physical effort. J Sport Exerc Psychol 29:78-99

83. Podewils LJ, Guallar E, Kuller LH, Fried LP, Lopez OL, Carlson M, Lyketsos CG (2005) Physical activity, APOE genotype, and dementia risk: findings from the Cardiovascular Health Cognition Study. Am J Epidemiol 161:639-651, doi:10.1093/aje/kwi092

84. Preusser DF, Williams AF, Ferguson SA, Ulmer RG, Weinstein HB (1998) Fatal crash risk for older drivers at intersections. Accid Anal Prev 30:151-159, doi:10.1016/S0001-4575(97) 00090-0

85. Raghuram A, Lakshminarayanan V (2006) Motion perceptions tasks as potential correlates to driving difficulty in the elderly. J Mod Opt 53:1343-1362, doi:10.1080/09500340 600619320

86. Recarte MA, Nunes LM (2003) Mental workload while driving: effects on visual search, discrimination, and decision making. J Exp Psychol Appl 9:119-137, doi:10.1037/1076898X.9.2.119

87. Reger MA, Welsh RK, Watson GS, Cholerton B, Baker LD, Craft S (2004) The relationship between neuropsychological functioning and driving ability in dementia: a metaanalysis. Neuropsychology 18:85-93, doi:10.1037/08944105.18.1.85

88. Richardson ED, Marottoli RA (2003) Visual attention and driving behaviors among community-living older persons. J Gerontol A Biol Sci Med Sci 58:M832-M836

89. Rockwood K, Middleton L (2008) Physical activity and the maintenance of cognitive function. Alzheimers Dement 3:S38S44, doi:10.1016/j.jalz.2007.01.003

90. Roenker DL, Cissell GM, Ball KK, Wadley VG, Edwards JD (2003) Speed-of-processing and driving simulator training result in improved driving performance. Hum Factors 45:218-233, doi:10.1518/hfes.45.2.218.27241

91. Rogé J, Otmani S, Pébayle T, Muzet A (2008) The impact of age on useful visual field deterioration and risk evaluation in a simulated driving task. Eur Rev Appl Psychol 58:5-12, doi:10.1016/j.erap.2006.04.001

92. Rosenbloom S (2001) Sustainability and automobility among the elderly: an international assessment. Transportation 28:375-408, doi:10.1023/A:1011802707259

93. Rosenbloom S (1993) Transportation needs of the elderly population. Clin Geriatr Med 9:297-310

94. Roth DL, Goode KT, Clay OJ, Ball KK (2003) Association of physical activity and visual attention in older adults. J Aging Health 15:534-547, doi:10.1177/0898264303253512

95. Rubin GS, Ng ES, Bandeen-Roche K, Keyl PM, Freeman EE, West SK (2007) A prospective, population-based study of the role of visual impairment in motor vehicle crashes among older drivers: the SEE study. Invest Ophthalmol Vis Sci 48:14831491, doi:10.1167/iovs.06-0474
96. Sagberg F (2006) Driver health and crash involvement: a casecontrol study. Accid Anal Prev 38:28-34, doi:10.1016/j. aap.2005.06.018

97. Salthouse TA (1985) Speed of behavior and its implications for cognition. In: Birren JE, Schaie KW (eds) Handbook of the psychology of aging. Van Nostrand Reinhold, New York, pp 400-426

98. Sanders AF (1970) Some aspects of the selective process in the functional visual field. Ergonomics 13:101-117, doi:10.1080/ 00140137008931124

99. Schiff W, Oldak R, Shah V (1992) Aging persons' estimates of vehicular motion. Psychol Aging 7:518-525, doi:10.1037/08827974.7.4.518

100. Seiple W, Szlyk JP, Yang S, Holopigian K (1996) Age-related functional field losses are not eccentricity dependent. Vision Res 36:1859-1866, doi:10.1016/0042-6989(95)00288-X

101. Sekuler AB, Bennett PJ, Mamelak M (2000) Effects of aging on the useful field of view. Exp Aging Res 26:103-120, doi: $10.1080 / 036107300243588$

102. Shay KA, Roth DL (1992) Association between aerobic fitness and visuospatial performance in healthy older adults. Psychol Aging 7:15-24, doi:10.1037/0882-7974.7.1.15

103. Shea CH, Park JH, Braden HW (2006) Age-related effects in sequential motor learning. Phys Ther $86: 478-488$

104. Simões A (2003) The cognitive training needs of older drivers. Recherche Transports Sécurite 79:145-155

105. Sims RV, McGwin G Jr, Allman RM, Ball K, Owsley C (2000) Exploratory study of incident vehicle crashes among older drivers. J Gerontol A Biol Sci Med Sci 55: M22-M27

106. Sims RV, McGwin G Jr, Pulley LV, Roseman JM (2001) Mobility impairments in crash-involved older drivers. J Aging Health 13:430-438, doi:10.1177/089826430101300306

107. Sims RV, Owsley C, Allman RM, Ball K, Smoot TM (1998) A preliminary assessment of the medical and functional factors associated with vehicle crashes by older adults. J Am Geriatr Soc 46:556-561

108. Skaar N, Rizzo M, Stierman L (2003) Traffic entry judgments by aging drivers. In: Second International Driving Symposium on Human Factors in Driver Assessment, Training and Vehicle Design. Park City, Utah, p 92-97

109. Smith CD, Umberger GH, Manning EL, Slevin JT, Wekstein DR, Schmitt FA, Markesbery WR, Zhang Z, Gerhardt GA, Kryscio RJ, Gash DM (1999) Critical decline in fine motor hand movements in human aging. Neurology $53: 1458-1461$

110. Spirduso WW (2006) Issues of aging, physical activity, cognition and putative mechanisms for a relationship: a discussion. In: Poon LW, Chodzko-Zajko W, Tomporowski PD (eds) Active living, cognitive functioning and aging. Human Kinetics, Champaign, pp 187-195

111. Spirduso WW, Francis KL, MacRae PG (2005) Physical dimensions of aging, 2nd edn. Human Kinetics, Champaign

112. Stelmach GE, Nahom A (1992) Cognitive-motor abilities of the elderly driver. Hum Factors 34:53-65

113. Tay R (2006) Ageing drivers: storm in a teacup? Accid Anal Prev 38:112-121, doi:10.1016/j.aap.2005.07.009

114. Tuokko H, Tallman K, Beattie BL, Cooper P, Weir J (1995) An examination of driving records in a dementia clinic. J Gerontol B Psychol Sci Soc Sci 50:S173-S181

115. Tuokko HA, Rhodes RE, Dean R (2007) Health conditions, health symptoms and driving difficulties in older adults. Age Ageing 36:389-394, doi:10.1093/ageing/afm032

116. van Boxtel MP, Paas FG, Houx PJ, Adam JJ, Teeken JC, Jolles J (1997) Aerobic capacity and cognitive performance in a cross- 
sectional aging study. Med Sci Sports Exerc 29:1357-1365, doi:10.1097/00005768-199710000-00013

117. Waller PF (1991) The older driver. Hum Factors 33:499-505

118. Whelihan WM, DiCarlo MA, Paul RH (2005) The relationship of neuropsychological functioning to driving competence in older persons with early cognitive decline. Arch Clin Neuropsychol 20:217-228, doi:10.1016/j.acn.2004.07.002

119. Williams AF (1989) Driver age and crash involvement. Am J Public Health 79:326-327, doi:10.2105/AJPH.79.3.326
120. World Health Organization (1997) The Heidelberg guidelines for promoting physical activity among older persons. J Aging Phys Act 5:2-8

121. Zhang L, Baldwin K, Munoz B, Munro C, Turano K, Hassan S, Lyketsos C, Bandeen-Roche K, West SK (2007) Visual and cognitive predictors of performance on brake reaction test: Salisbury eye evaluation driving study. Ophthalmic Epidemiol 14:216-222, doi:10.1080/092865807 01502988 